\title{
CẢI TIẾN PHƯƠNG PHÁP KIỂM TRA ĐÁNH GIÁ MÔN KẾT CẤU THÉP CƠ BẢN CHUYÊN NGÀNH KỸ THUẬT XÂY DỤ̂NG
}

\author{
Võ Thanh Hùng ${ }^{(*)}$ \\ (*) Thạc sĩ. Truò̀ng Đại học Thủ Dầu Một. Email: hungvt@tdmu.edu.vn
}

DOI: $10.37550 /$ tdmu.CFR/2021.01.137

\section{Tóm tắt}

Kiểm tra đánh giá kết quả học tập của người học là một khâu quan trọng trong quá trình dạy hoc, nhằm xác định mưc độ học tập của người học có đạt được theo muc tiêu của chuẩn đầu ra môn học hay không. Nếu việc kiểm tra đánh giá được thực hiện chính xác và minh bach, thì đó sẽ là nhũng căn cú để điều chỉnh phương pháp dạy học và có tác dụng khuyến khích người học tích cưc học tập. Theo xu hướng hiện nay, nguời dạy cần phải phổ biến các tiêu chí đánh giá của môn học cho người học biết để người học có thể chủ động trong quá trình học tập, lựa chọn cách tiếp cận môn học phù hợp với các tiêu chí đánh giá, tù̀ đó có thể đánh giá mức độ hiểu rõ môn học của chính người họ.

Từ khóa: Kiểm tra đánh giá, người dạy, người học, Rubrics, kỹ thuật xây dụng

\section{1. Đặt vấn đề}

Kiểm tra đánh giá kết quả học tập của người học là một khâu quan trọng trong quá trình dạy học, nhằm xác định mức độ học tập của người học có đạt được mục tiêu của chuẩn đầu ra môn học hay không. Nếu việc kiểm tra đánh giá được thực hiện chính xác và minh bạch, thì đó sẽ là những căn cứ để điều chỉnh phương pháp dạy học và có tác dụng khuyến khích người học tích cực học tập.

Nguyên tắc quan trọng của kiểm tra đánh giá là minh bạch từ kết quả học tập cho đến mục tiêu và yêu cầu của kết quả đánh giá. Theo xu hướng hiện nay, người dạy cần phải phổ biến các tiêu chí đánh giá của môn học cho người học biết để người học có thể chủ động trong quá trình học tập, lựa chọn cách tiếp cận môn học phù hợp với các tiêu chí đánh giá, từ đó có thể đánh giá mức độ hiểu rõ môn học của chính người học.

Để việc xây dựng các tiêu chí đánh giá, người dạy cần phải nắm vững các kỹ thuật thiết kế tiêu chí đánh giá phù hợp theo phương thức tiếp cận CDIO.

Ngành kỹ thuật xây dựng là ngành học trang bị cho người học kiến thức về toán ứng dụng, vật lý kỹ thuật, phần mềm thiết kế chuyên sâu trong lĩnh vực xây dựng và kiến thức 
nền tảng về xây dựng công trình dân dụng và công nghiệp. Trong quá trình dạy học, kiểm tra đánh giá là một khâu quan trọng nhằm xác định mức độ hiểu biết về kiến thức, kỹ năng, và khả năng vận dụng của người học.

\section{Thực trạng kiểm tra đánh giá và kết quả học tập môn kết câu thép cơ bản}

\subsection{Thục trạng kiểm tra đánh giá}

Phương pháp kiểm tra đánh giá môn kết cấu thép cơ bản được chia thành hai phần:

- Điểm đánh giá quá trình học tập của người học trên lớp bao gồm: bài thu hoạch của từng người học và bài tập nhóm.

- Điểm đánh giá cuối học kỳ: bao quát tất cả nội dung học và được gói gọn trong 2 câu bài tập.

Bảng 1. Hình thức đánh giá theo nội dung đề cuơng 2016

\begin{tabular}{|l|l|}
\hline \multicolumn{1}{|c|}{ Thành phần đánh giá } & \multicolumn{1}{c|}{$\begin{array}{c}\text { Hình thức đánh giá } \\
(\mathrm{Ax} . \mathrm{x})\end{array}$} \\
\hline \multirow{2}{*}{ A1. Đánh giá quá trình } & Bài thu hoạch trên lớp của mỗi sinh viên \\
\cline { 2 - 3 } & Bài tập nhóm \\
\hline A2. Đánh giá cuối kỳ & Tự luận (được sử dụng tài liệu) \\
\hline
\end{tabular}

\subsection{Kết quả học tập môn kết cấu thép cơ bản}

Bảng 2. Kết quả đánh giá môn học kết cấu thép cơ bản

\begin{tabular}{|l|c|c|c|c|c|}
\hline \multirow{2}{*}{} & \multicolumn{5}{|c|}{ Kết quả đánh giá } \\
\cline { 2 - 6 } & Năm học & $\begin{array}{c}\text { Số lượng người } \\
\text { học đạt yêu cầu }\end{array}$ & $\begin{array}{c}\text { Số lượng người } \\
\text { học không đạt } \\
\text { yêu cầu }\end{array}$ & $\begin{array}{c}\text { Tồng số } \\
\text { người học }\end{array}$ & $\begin{array}{c}\text { Tỷ lệ người học } \\
\text { đạt yêu cầu }\end{array}$ \\
\hline D14XD01,02,03 & $2016-2017$ & 10 & 82 & 92 & 10,87 \\
\hline D15XD01 & $2017-2018$ & 6 & 50 & 56 & 10,71 \\
\hline D16XDDD & $2018-2019$ & 4 & 58 & 62 & 6,45 \\
\hline D17XDDD & $2019-2020$ & 2 & 55 & 57 & 3,51 \\
\hline
\end{tabular}

Từ bảng 1 , ta thấy kết quả học tập của người học đạt yêu cầu rất thấp, đặt ra vấn đề phương pháp giảng dạy của người dạy, phương pháp kiểm tra đánh giá người học cũng như quá trình học tập của người học.

Từ thực trạng của người học đối với môn học chuyên ngành của ngành kỹ thuật xây dựng, cần sự đổi mới về phương pháp giảng dạy cũng như đổi mới phương pháp kiểm tra đánh giá, để giúp người học nhìn nhận rõ bản thân xem kết quả học tập của mình đạt mức nào/đến đâu so với yêu cầu, tốt hay chưa tốt như thế nào. Với cách hiểu đánh giá ấy mới 
giúp hình thành năng lực của người học, tạo cơ hội cho người học phát triển kĩ năng tự đánh giá, giúp người học nhận ra sự tiến bộ của mình, khuyến khích động viên việc học tập.

Với kết quả học tập của sinh viên từ bảng 1 đạt kết quả không được như kỳ vọng, cùng với yêu cầu cải tiến nội dung đề cương đảm bảo theo yêu cầu kiểm định. Từ năm học 2020-2021, người dạy đã tiến hành cải tiến nội dung đề cương môn học kết cấu thép cơ bản, kèm theo sự thay đổi về phương pháp kiểm tra đánh giá người học.

\section{Nội dung cải tiến phương pháp kiểm tra đánh giá}

\subsection{Xây dụng tiêu chí đánh giá môn học theo Rubrics}

Có nhiều nghiên cứu nêu định nghĩa về Rubrics, xét về ngôn từ tuy khác nhau, nhưng về mặt ý nghĩa thì có nhiều điều giống nhau.

Theo Nguyễn Kiều và Nguyễn Thị Lan Phương (2009), Rubrics là bản mô tả đầy đủ những gì người học cần chứng tỏ để được xếp hạng năng lực giỏi, khá, trung bình, yếu, kém đối với yêu cầu môn học.

Theo Lê Thị Ngọc Nhẫn (2014), Rubrics là công cụ dùng để đánh giá kết quả học tâp của người học được thể hiện bằng bản mô tả các tiêu chí đánh giá theo các cấp độ khác nhau trên cơ sở các yêu cầu, mục tiêu cần đạt của môn học

Đối với người học, Rubrics được thiết kế để giúp người học hiểu rõ hơn các mong đợi của người dạy, của chương trình đào tạo, của nhà trường. Từ đó, người học sẽ có được động lực học tập tốt hơn, chủ động hơn, tích cực hơn, có trách nhiệm hơn, có thể tự đánh giá việc học tập của mình.

Đối với người dạy, Rubrics được thiết kế giúp người dạy định hình các nội dung về yêu cầu của từng bài học, từng môn học, từng chuyên đề để từ đó giúp người dạy thiết kế bài giảng, tổ chức bài giảng và hướng dẫn người học đạt được yêu cầu của môn học. Ngoài ra, Rubrics còn làm cho việc đánh giá trở nên khoa học, minh bạch và thuyết phục. Việc chấm bài sẽ trở nên khoa học và nhất quán, tạo sự công bằng cho người học.

\subsection{Kiểm tra đánh giá phần tụ học của ngưòi học}

Mục tiêu của kiểm tra đánh giá phần tự học của người học là để có những hiểu biết về những gì người học biết (và không biết) nhằm tạo ra những thay đổi trong quá trình dạy và học. Giúp người học củng cố lại kiến thức đã được học trên lớp. Phần tự học của người học sẽ được đánh giá qua các bài tự luận trên hệ thống E- learning. Thông qua hệ thống Elearning, người dạy có thể nắm bắt được việc học của người học và từ đó có sự điều chỉnh trong quá trình dạy học, cũng như nhắc nhở người học về việc học.

Úng với sau từng buổi học, trên hệ thống E- learning sẽ có bài tập tương ứng yêu cầu người học phài hoàn thành trong tuần, và sẽ khóa lại đối với phần bài tập đó khi người dạy giảng dạy bài giảng tiếp theo. Từ đó, người học sẽ có trách nhiệm và tích cực hơn trong môn học. 
Bảng 3. Rubrics hoàn thành bài tập tụ luận trên hệ thống E-Learning

\begin{tabular}{|c|c|c|c|c|c|}
\hline Tiêu chí đánh giá & \multicolumn{1}{|c|}{$\begin{array}{c}\text { Tốt } \\
(9-10 \text { điểm })\end{array}$} & $\begin{array}{c}\text { Khá } \\
(7-8 \text { điểm })\end{array}$ & $\begin{array}{c}\text { Đạt } \\
(5-6 \text { điểm })\end{array}$ & $\begin{array}{c}\text { Chưa đạt } \\
(<5 \text { điềm })\end{array}$ & $\begin{array}{c}\text { Trọ́ng } \\
\text { số }\end{array}$ \\
\hline Bố cục trình bày & $\begin{array}{l}\text { Cân đối, hợp } \\
\text { lý }\end{array}$ & $\begin{array}{c}\text { Khá cân đối, } \\
\text { hợp lý }\end{array}$ & $\begin{array}{c}\text { Tương đối cân đối, hợp } \\
\text { lý }\end{array}$ & $\begin{array}{c}\text { Không cân đối, } \\
\text { thiếu hợp lý }\end{array}$ & 20 \\
\hline Nội dung bài làm & $\begin{array}{l}\text { Rất chính } \\
\text { xác }\end{array}$ & Chính xác & $\begin{array}{c}\text { Còn sai sót nhỏ không } \\
\text { gây ảnh hưởng }\end{array}$ & Nhiều sai sót & 80 \\
\hline
\end{tabular}

\subsection{Kiểm tra đánh giá quá trình tham dụ lớp của nguòi học}

Mục tiêu của kiểm tra đánh giá quá trình tham dự lớp của người học nhằm mục đích giúp người dạy có thể quản lý lớp học, nắm bắt rõ hơn tình hình học tập của người học.

Có nhiều hình thức để kiểm tra đánh giá quá trình tham dự lớp của người học:

- Phương pháp đặt câu hỏi và thảo luận lớp học: phương pháp này được xem là cơ hội để làm tăng thêm kiến thức và nâng cao sự hiểu biết của người học. Phát huy tinh thần làm việc theo nhóm. Người học phải có kiến thức sâu và rộng thì mới có thể đáp ứng được yêu cầu của người dạy, buộc người học phải tự giác tìm tòi tài liệu liên quan đến bài học.

- Phương pháp làm việc nhóm : Do mục tiêu của đánh giá quá trình là để có những hiểu biết về những gì sinh viên biết (và không biết) nhằm tạo ra những thay đổi trong quá trình dạy và học, các kỹ thuật chẳng hạn như quan sát của người dạy và thảo luận trong lớp học cũng có một vị thế quan trọng bên cạnh các phân tích bài kiểm tra và bài tập về nhà. Nên người dạy có thể sử dụng các phương pháp làm việc nhóm như phương pháp đánh giá. Người học chủ động, sáng tạo, nghiêm túc trong quá trình học và chuẩn bị bài.

Bảng 4. Rubrics tham dụ lớp

\begin{tabular}{|l|c|c|c|c|}
\hline \multicolumn{1}{|c|}{ Tiêu chí } & $\begin{array}{c}\text { Tốt } \\
(9-10 \text { điểm })\end{array}$ & $\begin{array}{c}\text { Khá } \\
(7-8 \text { điểm })\end{array}$ & $\begin{array}{c}\text { Đạt } \\
(5-6 \text { điểm })\end{array}$ & $\begin{array}{c}\text { Chưa đạt } \\
(<5 \text { điêm })\end{array}$ \\
\hline Thời gian tham dự & $\begin{array}{c}90-100 \% \\
(6 đ)\end{array}$ & $\begin{array}{c}80-89 \% \\
(5 đ)\end{array}$ & $\begin{array}{c}60-789 \% \\
(4 đ)\end{array}$ & $\begin{array}{c}\text { Ít hơn } 60 \% \\
(<4 \text { đ })\end{array}$ \\
\hline Thái độ tham dự & $\begin{array}{c}\text { Đóng góp ý kiến } \\
\text { từ } 5 \text { lần trở lên } \\
(4 đ)\end{array}$ & $\begin{array}{c}\text { Đóng góp ý kiến từ } \\
3-4 \text { lần } \\
(3 đ)\end{array}$ & $\begin{array}{c}\text { Đóng góp ý } \\
\text { kiến từ } 1-2 \text { lần } \\
(1 \text { đ })\end{array}$ & $\begin{array}{c}\text { Không đóng } \\
\text { góp } \\
(0 \text { đ })\end{array}$ \\
\hline
\end{tabular}

\subsection{Kiểm tra đánh giá kết thúc học phần}

Trong quá trình dạy học, kiểm tra đánh giá là một khâu quan trọng nhằm xác định mức độ hiểu biết về kiến thức, kỹ năng, và khả năng vận dụng của người học. Đối với người học, nhân vật trung tâm của quá trình dạy học, kiểm tra, đánh giá có tác dụng thúc đẩy quá trình học tập phát triển không ngừng.

Kiểm tra đánh giá kết thúc học phần sẽ là tổng hợp của các nội dung của môn học kết cấu thép cơ bản: 1) Thiết kế liên kết trong kết cấu thép; 2) Thiết kế dầm thép; 3) Thiết kế cột thép.

Cách đánh giá kết thúc học phần sẽ thông qua việc nộp bài tiểu luận và thi vấn đáp. Cấu trúc bài tiểu luận sẽ thể hiện đầy đủ nội dung mà người học đã được học, đề tiểu luận 
được tổ chức thành nhiều dạng đề khác nhau và với nhiều số liệu khác nhau để tất cả người học đều có được một bộ đề riêng biệt, nhằm mục đích tất cả người học đều phải làm bài tiểu luận. Thông qua bài tiểu luận nộp cuối khóa người học sẽ được củng cố lại tất cả kiến thức mà mình đã được học.

Nội dung bài tiểu luận là những dạng kết cấu nhỏ trong công trình kết cấu nhà thép, trụ cột bảng quảng cáo... nhằm giúp người học có cái nhìn trực quan về môn học kết cấu thép co bản, từ đó sẽ hiểu rõ việc thiết kế công trình sẽ cần bắt đầu từ đâu và các bước làm việc như thế nào để tạo ra được sản phẩm thiết kế bao gồm: thuyết minh tính toán và bản vẽ thi công.

Bảng 5. Rubrics đánh giá bài tiểu luận

\begin{tabular}{|l|l|c|c|c|c|}
\hline Tiêu chí đánh giá & \multicolumn{1}{|c|}{$\begin{array}{c}\text { Tốt } \\
(9-10 \text { điểm })\end{array}$} & $\begin{array}{c}\text { Khá } \\
(7-8 \text { điểm })\end{array}$ & $\begin{array}{c}\text { Đạt } \\
(5-6 \text { điểm })\end{array}$ & $\begin{array}{c}\text { Chưa đạt }(<5 \\
\text { điêm) }\end{array}$ & $\begin{array}{c}\text { Trọng } \\
\text { số }\end{array}$ \\
\hline Giải pháp liên kết & Rất hợp lý & Hợp lý & Tương đối hợp lý & Không hợp lý & 20 \\
\hline Tính toán liên kết & $\begin{array}{l}\text { Rất chính } \\
\text { xác }\end{array}$ & Chính xác & $\begin{array}{c}\text { Còn sai sót nhỏ } \\
\text { không gây ảnh } \\
\text { hương }\end{array}$ & Nhiều sai sót & 25 \\
\hline Bố cục trình bày & $\begin{array}{l}\text { Cân đối, hợp } \\
\text { lý }\end{array}$ & $\begin{array}{c}\text { Khá cân đối, } \\
\text { hợp lý }\end{array}$ & $\begin{array}{c}\text { Tương đối cân } \\
\text { đối, hợp lý }\end{array}$ & $\begin{array}{c}\text { Không cân đối, } \\
\text { thiếu hợp lý }\end{array}$ & 5 \\
\hline Giải pháp kết cấu & Rất hợp lý & Hợp lý & $\begin{array}{c}\text { Tương đối hợp lý } \\
\text { Không hợp lý }\end{array}$ & 20 \\
\hline $\begin{array}{l}\text { Tính toán các cấu } \\
\text { kiện }\end{array}$ & $\begin{array}{l}\text { Rất } \\
\text { xác chính }\end{array}$ & Chính xác & $\begin{array}{c}\text { Còn sai sót nhỏ } \\
\text { không gây ảnh } \\
\text { hưởng }\end{array}$ & Nhiều sai sót & 25 \\
\hline Bố cục trình bày & $\begin{array}{l}\text { Cân đối, hợp } \\
\text { lý }\end{array}$ & $\begin{array}{c}\text { Khá cân đối, } \\
\text { hợp lý }\end{array}$ & $\begin{array}{c}\text { Tương đối cân } \\
\text { đối, hợp lý }\end{array}$ & $\begin{array}{c}\text { Không cân đối, } \\
\text { thiếu hợp lý }\end{array}$ & 5 \\
\hline
\end{tabular}

Cách chấm thi vấn đáp, sẽ được tổ chức sau hai tuần kết thúc môn học và một hội đồng chấm bao gồm 2 thành viên. Thành viên hội đồng chấm thi vấn đáp bao gồm người trực tiếp giảng dạy và một thành viên giảng dạy tương đồng về chuyên môn.

Nội dung câu hỏi thi vấn đáp sẽ bao hàm tất cả nội dung mà người học đã được học trong học phần kết cấu thép cơ bản. Việc thi vấn đáp, sẽ giúp người dạy đánh giá trực tiếp mức độ người học lĩnh hội kiến thức chiếm tỷ lệ bao nhiêu so với mục tiêu người dạy đặt ra trong giảng dạy.

Bảng 6. Rubrics đánh giá trả lời vấn đáp

\begin{tabular}{|l|l|c|c|c|c|}
\hline \multicolumn{1}{|c|}{ Tiêu chí đánh giá } & \multicolumn{1}{|c|}{$\begin{array}{c}\text { Tốt } \\
(9-10 \text { điểm })\end{array}$} & $\begin{array}{c}\text { Khá } \\
(7-8 \text { điểm })\end{array}$ & $\begin{array}{c}\text { Đạt } \\
(5-6 \text { điểm })\end{array}$ & $\begin{array}{c}\text { Chưa đạt }(<5 \\
\text { điểm })\end{array}$ & $\begin{array}{c}\text { Trọng } \\
\text { số }\end{array}$ \\
\hline $\begin{array}{l}\text { Mức độ tự tin khi } \\
\text { trả lời }\end{array}$ & Rất tự tin & Tự tin & Tương đối tự tin & Không tự tin & 15 \\
\hline Nội dung trả lời & $\begin{array}{l}\text { Rất chính } \\
\text { xác }\end{array}$ & Chính xác & $\begin{array}{c}\text { Còn sai sót nhỏ không } \\
\text { gây ảnh hưởng }\end{array}$ & Nhiều sai sót & 50 \\
\hline Bố cục trả lời & $\begin{array}{l}\text { Lôgic, hợp } \\
\text { lý }\end{array}$ & $\begin{array}{c}\text { Khá lôgic, } \\
\text { hợp lý }\end{array}$ & $\begin{array}{c}\text { Tương đối lôgic, hợp } \\
\text { lý }\end{array}$ & $\begin{array}{c}\text { Không lôgic, } \\
\text { thiếu hợp lý }\end{array}$ & 35 \\
\hline
\end{tabular}




\subsection{Nội dung bài giảng sau khi cải tiến phương pháp kiểm tra đánh giá}

Bảng 7. Nội dung bài giảng sau khi cải tiến phương pháp kiểm tra đánh giá

\begin{tabular}{|c|c|c|}
\hline Buổi & Nội dung & Hoạt động dạy, học và đánh giá \\
\hline 1 & $\begin{array}{l}\text { - Giới thiệu về học phần } \\
\text { Chương } 1 \text {. Vật liệu và sự làm việc của kết cấu } \\
\text { thép } \\
\text { 1.1. Thép xây dựng } \\
\text { 1.2. Sự làm việc của thép chịu tải trọng } \\
\text { 1.3. Qui cách thép cán dùng trong xây dựng } \\
\text { 1.4. Phương pháp tính kết cấu thép } \\
\text { 1.5 Tính toán câu kiện } \\
\text { Chương 2. Liên kết } \\
\text { A. Liên kết hàn } \\
\text { 2.1 Các phương pháp hàn trong kết cấu thép } \\
\text { 2.2 Phân loại đường hàn } \\
\text { 2.3 Tính toán đường hàn } \\
\text { 2.3.1 Tính toán đường hàn đối đầu } \\
\text { 2.3.2 Tính toán đường hàn góc } \\
\text { 2.4 Úng suất hàn - biến hình hàn }\end{array}$ & $\begin{array}{l}\text { Hoạt động dạy: } \\
\text { Thuyết giảng, trình chiếu, thảo luận } \\
\text { Hoạt động tự học: } \\
\text { - Làm bài tập ợ nhà (E- learning) } \\
\text { - Đọc trước nội dung của buổi học thứ } 2 \text { và làm } \\
\text { trắc nghiệm trên E- learning } \\
\text { Hoạt động đánh giá: } \\
\text { - Bài thu hoạch về tính toán đường hàn góc. } \\
\text { - Điểm danh trên lớp. }\end{array}$ \\
\hline 2 & $\begin{array}{l}\text { Chương 2. Liên kết } \\
\text { B. Liên kết bu lông } \\
\text { 2.5 Các loại bu lông dùng trong kết cấu thép } \\
\text { 2.6 Sự làm việc của bu lông và khả năng chịu } \\
\text { lực của bu lông } \\
\text { 2.7 Cấu tạo của liên kết bulông } \\
\text { 2.8 Tính toán liên kết bu lông } \\
\text { Chương 3. Dầm thép } \\
\text { 3.1 Đại cương về dầm và hệ dầm } \\
\text { 3.2 Thiết kế dầm thép hình } \\
\text { 3.3 Thiết kế dầm tổ hợp }\end{array}$ & $\begin{array}{l}\text { Hoạt động dạy: } \\
\text { Thuyết giảng, trình chiếu, thảo luận } \\
\text { Hoạt động tự học: } \\
\text { - Làm bài tập ợ nhà (E- learning) } \\
\text { - Đọc trước nội dung của buổi học thứ } 3 \\
\text { Hoạt động đánh giá: } \\
\text { - Bài thu hoạch về tính toán liên kết bu lông } \\
\text { chịu tác dụng của mô men vuông góc với mặt } \\
\text { phắng bố trí bu lông } \\
\text { - Điê̂m danh trên lớp }\end{array}$ \\
\hline 3 & $\begin{array}{l}\text { Chương 3. Dầm thép } \\
\text { 3.4 Cấu tạo và tính toán các chi tiết của dầm } \\
\text { Chương 4. Cột thép } \\
\text { 4.1 Khái quát chung } \\
\text { 4.2 Cột đặc chịu nén đúng tâm }\end{array}$ & $\begin{array}{l}\text { Hoạt động dạy: } \\
\text { Thuyết giảng, trình chiếu, thảo luận } \\
\text { Hoạt động tự học: } \\
\text { - Làm bài tập ở nhà (E- learning) } \\
\text { - Đọc trước nội dung của buổi học thứ } 4 \\
\text { Hoạt động đánh giá: } \\
\text { - Bài thu hoạch về kiềm tra cột đặc nén đúng tâm } \\
\text { - Điểm danh trên lớp }\end{array}$ \\
\hline 4 & $\begin{array}{l}\text { Chương 4. Cột thép } \\
4.3 \text { Cột rỗng chịu nén đúng tâm } \\
\text { - Cột rô̂ng thanh giằng } \\
\text { - Cột rỗng bản giẳng }\end{array}$ & $\begin{array}{l}\text { Hoạt động dạy: } \\
\text { Thuyết giảng, trình chiếu, thảo luận } \\
\text { Hoạt động tự học: } \\
\text { - Làm bài tập ợ nhà (E- learning) } \\
\text { - Đọc trước nội dung của buổi học thứ } 5 \\
\text { Hoạt động đánh giá: } \\
\text { - Bài thu hoạch về kiểm tra cột rỗng thanh giằng } \\
\text { nén đúng tâm } \\
\text { - Điểm danh trên lớp }\end{array}$ \\
\hline 5 & $\begin{array}{l}\text { Chương 4. Cột thép } \\
\text { 4.4 Cấu tạo và tính toán các chi tiết của cột } \\
\text { Chương 5. Dàn thép } \\
5.1 \text { Đại cương về dàn thép }\end{array}$ & $\begin{array}{l}\text { Hoạt động dạy: } \\
\text { Thuyết giảng, trình chiếu, thảo luận } \\
\text { Hoạt động tự học: } \\
\text { - Làm bài tập ở nhà (E- learning) } \\
\text { - Đọc trước nội dung của buổi học thứ } 6 \\
\text { Hoạt động đánh giá: } \\
\end{array}$ \\
\hline 6 & $\begin{array}{l}\text { Chương 5. Dàn thép } \\
5.2 \text { Tính toán dàn }\end{array}$ & $\begin{array}{l}\text { Hoạt động dạy: } \\
\text { Hướng dẫn sinh viên làm việc nhóm }\end{array}$ \\
\hline
\end{tabular}




\begin{tabular}{|l|l|l|}
\hline 5.3 Cấu tạo và tính toán nút dàn & $\begin{array}{l}\text { Hoạt động tự học: } \\
\text { - Làm bài tập ở nhà (E- learning) } \\
\text { Hoạt động đánh giá: }\end{array}$ \\
& $\begin{array}{l}\text { - Kết quả làm nhóm của sinh viên } \\
\text { - Điểm danh trên lớp }\end{array}$ \\
\hline
\end{tabular}

Nội dung đề cương được soạn cho sáu buổi học và một buổi học bao gồm năm tiết. Từng buổi học đều trình bày rõ ràng từng nội dung yêu cầu đối với người dạy, yêu cầu người học cần hoàn thành đầy đủ nội dung theo lịch trình giảng dạy. Nếu số buổi học được tăng thêm do số tiết trong một buổi học giảm đi thì nội dung yêu cầu của từng chương sẽ càng chi tiết hơn và kết quả của việc kiểm tra đánh giá sẽ chính xác hơn đối với người học.

\section{Kiến nghị}

Việc cải tiến phương pháp kiểm tra đánh giá môn kết cấu thép cơ bản thuộc chuyên ngành Kỹ thuật xây dựng nhằm giúp người dạy đánh giá được sự phù hợp của phương pháp giảng dạy, tạo sự gần gũi giữa người dạy và người học, đánh giá một cách chính xác sự tiếp thu và khả năng hiểu bài của người học.

Việc cải tiến phương pháp kiểm tra đánh giá môn Kết cấu thép cơ bản thuộc chuyên ngành Kỹ thuật xây dựng nhằm giúp người học nhận thức đúng đắn về môn học chuyên ngành, cung cấp cho người học các kiến thức cần thiết trong việc tiếp cận công việc tính toán thiết kế công trình kết cấu thép.

Việc cải tiến phương pháp kiểm tra đánh giá môn kết cấu thép cơ bản nhằm đánh giá chính xác khả năng tự học, khả năng tự tìm kiếm các tài liệu về chuyên ngành, cũng như tìm hiểu về các bộ tiêu chuẩn gắn bó với công việc tính toán thiết kế kết cấu thép của Việt Nam cũng như quốc tế.

Kiểm tra đánh giá có ý nghĩa vô cùng quan trọng đối với người học, người dạy. Với những cải tiến phương pháp kiểm tra đánh giá đã trình bày có thể đáp ứng được những yêu cầu đã được đặt ra

\section{Tài liệu tham khảo}

[1] Lê Thị Ngọc Nhẫn (2014), Vận dụng Rubrics để xây dựng các tiêu chí đánh giá môn học, Tạp chí khoa học Đại học sư phạm TPHCM, số 62 năm 2014, tr. 146 - 151.

[2] Nguyễn Kiều và Nguyễn Thị Lan Phương (2009), Chỉ đạo đổi mói đánh giá kết quả học tập của học sinh, Hà Nội .

[3] Đề cương môn học Kết cấu thép cơ bản, 2016, Bộ môn Kết cấu, Khoa Xây dựng, Đại học Thủ Dầu Một.

[4] Đề cương môn học Kết cấu thép cơ bản, 2020, Chương trình Kỹ thuật xây dựng, Khoa Kiến trúc, Đại học Thủ Dầu Một. 